\title{
Argument omissions in preschool Catalan and Spanish speaking children with SLI
}

\author{
MÒNICA SANZ-TORRENT ${ }^{1}$, LLORENÇ ANDREU ${ }^{1,2}$, \\ IRIS BADIA ${ }^{1}$ AND FRANCESC SIDERA ${ }^{3}$ \\ ${ }^{1}$ Universitat de Barcelona; ${ }^{2}$ Universitat Oberta de Catalunya; ${ }^{3}$ Universitat de Girona
}

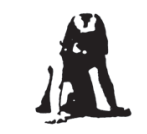

\begin{abstract}
This paper describes three studies on verb production and argument structure in children with Specific Language Impairment (SLI) using different methodologies. The first is an observational study which uses a spontaneous-talk longitudinal sample. The second uses an experimental sentence naming task as a result of event video observation. The third comprises an experimental sentence naming task with static images that differ in verb argument complexity. Although the specific data vary according to the methodology used, there is clear evidence that Catalan and Spanish speaking children with SLI have special difficulties in producing verbs with a bighly complex argument structure and make errors in the specification of obligatory arguments. It is concluded that both processing limitations and deficits in the semantic representation of verbs may play a role in these difficulties.
\end{abstract}

Keywords: Specific Language Impairment, psycholinguistics, language acquisition, verb processing, argument structure.

\section{Omisión de argumentos en niños de preescolar hablantes de catalán y español cOn TEL}

\begin{abstract}
Resumen
El presente artículo describe tres estudios sobre la producción del verbo y la estructura argumental en niños con Trastorno Específico del Lenguaje (TEL) usando diferentes metodologías. El primero es un estudio observacional que usa una muestra de habla espontánea. El segundo usa una tarea experimental de denominación de oraciones como resultado de la observación de videos de acciones. El tercero comprende la tarea de denominación de oraciones con imágenes estáticas en eventos con diferente complejidad argumental. Aunque los datos concretos varian en función de la metodología usada, hay una clara evidencia de que los niños de babla catalana y española con TEL presentan especiales dificultades en la producción de verbos con una alta complejidad en relación a la estructura argumental y cometen errores en la especificación de los argumentos obligatorios. Se concluye que tanto limitaciones en el procesamiento como déficits en la representación semántica de los verbos pueden estar implicados en estas dificultades.
\end{abstract}

Palabras clave: Trastorno Específico del Lenguaje, psicolingüística, adquisición del lenguaje, procesamiento del verbo, estructura argumental.

Acknowledgments: This paper has been partially financed by two grants, 2006ARIE1004 (from the Generalitat de Catalunya) and BS2003-02200 and SEJ2007-62743 (from MEC). We appreciate the help received from the CREDA centres, SPE-Castelló and their respective speech therapists, and would also like to thank Vicenç Bergas, Lucía Buil, Maica Hidalgo, Clara Machado, Eulalia Noguera, Miquel Serra, Elisabet Serrat for their help with certain aspects of the analysis and computation, and the anonymous reviewers for their help for improve the paper.

Corresponding Author: Llorenç Andreu Barrachina. Estudis de Psicologia i Ciències de l'Educació. Universitat Oberta de Catalunya. Rambla del Poble nou, 156.08018 Barcelona. E-mail: landreub@uoc.edu 


\section{Introduction}

Argument structure is a construct within linguistic theory that specifies the relation between the semantics of a lexical item and its syntactic expression, and as such serves as an important interface between lexis, syntax and semantics (e.g., Grimshaw, 2005; Jackendoff, 2002; Levin \& Rappaport, 1995). Jackendoff (2002) states that the verb defines the number of semantic arguments, and determines which of these arguments have to be expressed in the syntactic structure of the sentence in which the verb is embedded. For example, the verb "to kill" must have two arguments (the "agent" who executes the action and the "patient" who suffers from the action). In contrast, the verb "to give" has three arguments ("agent", "theme" and "recipient").

Many studies on semantic and syntactic development in children with normal language acquisition have focused especially on verb function and use, noting that the verb can contribute to grammar structure learning and thus provide a network for organising other types of words. Verb use has also been regarded as fundamental for linguistic advancement, a notion which has been confirmed in studies with children that have special problems in this area. There is a particular developmental language disorder, Specific Language Impairment (SLI), which is a developmental disorder characterised by no clear neurological, sensori-motor, non-verbal cognitive or social emotional deficits but which can affect both expressive and receptive language. The prevalence of this disorder in English speakers is "around $7 \%$ of the population, giving little restrictive diagnostic criteria, equally affecting both sexes but still more likely in males than in females" (Leonard, 1998).

One special characteristic of children with SLI is developmental delays in verbal abilities (Bishop, 1997; Leonard, 1998). Children with SLI have special difficulty with issues related to verb use (Conti-Ramsden \& Jones, 1997; Fletcher \& Peters, 1984; Kelly, 1997; Kelly \& Rice, 1994; Leonard, 1998; Rice \& Bode, 1993; Van del Lely, 1994; Watkins, Rice \& Moltz, 1993) because a characteristic they commonly share is a substantial delay in the use and understanding of functional morphology. SLI children's speech is characterized by a greater than normal misuse and dropping of inflectional morphology. These difficulties have been widely demonstrated in English (e.g., Grela \& Leonard, 2000; Hadley \& Rice, 1996; Leonard, 1995; Leonard, Eyer, Bedore \& Grela, 1997; Rice \& Wexler, 1996, 1997; Rice, Wexler, \& Cleave, 1995) as well as in other languages such as Swedish (Hansson, 1997), Croatian (Arapovic \& Andel, 2003), and German (Clahsen, 1989, 1991; Kerschensteiner \& Huber, 1975). In Catalan and Spanish, verb markers (person, number and tense) and auxiliary verbs are omitted, and there are mistakes with the use of the infinitive (Sanz-Torrent, Serrat, Andreu \& Serra, 2008).

Despite the problems found in relation to verbs, even today there are few studies on the development of argument structure in children with SLI. The majority of them were carried out in English and the results are often contradictory. While some studies find that children with SLI make more omissions and errors in the production of arguments than age controls, others do not. For example, Grela (2003) analyzed the omission of subject arguments in English-speaking children with SLI between 4;9 and 6;9 years. The participants were asked to produce sentences of varied argument structure complexity using a story completion task. The results indicated that both children with SLI and the Mean Length Utterance (MLU) controls omitted more grammatical subject arguments in ditransitive sentences than in sentences with intransitive and transitive verbs. In addition, more children with SLI omitted subjects as the 
linguistic complexity of the sentence increased. This effect was not found for the control children who never omitted subjects, regardless of increases in argument structure complexity. Grela argued that these results support the notion that grammatical errors in both children with SLI and their younger, normal counterparts may be due to problems with processing complex linguistic information rather than with limitations in linguistic knowledge.

Thordardottir and Weismer (2002) analyzed speech samples from 50 English speaking children with SLI (aged 5.5 - 9.8) and 50 children with normal language $(\mathrm{NL})$. They observed that the groups did not differ substantially in frequency of argument structure errors, particularly when pragmatic context was considered. However, children with SLI used significantly fewer argument types, argument structure types and verb alternations than age-matched children with NL. The authors suggested that a representational deficit may focus not on syntactic structure, but on semantic structure.

These differences may be due to multiple variables such as the use of different methodologies, the variablility in age of the children that took part in the studies or even features of the language of study. In fact, most data on this topic come from studies carried out on a language with poor verb morphology and a rigid word order, such as English. The typological characteristics of this type of language have a clear effect on language learning because children pay more attention to the characteristics that stand out more, or more often, or more regularly. Then, they have more types of errors in morphology, however, they don't have errors in word order because they are more exposed to these rules. This study was carried out on Spanish and Catalan languages that have a rich verb morphology and more flexible word order than English. Children in these languages make fewer errors in verb morphology than in English (Leonard, 2000), while they might be expected to make more errors in word order and argument structure omissions, since they are not exposed to such rigid and regular patterns.

Given that the typological characteristics of language may effect language learning, we sought to determine whether in Romance languages as Spanish and Catalan children with SLI show more errors of this type than those reported in Anglo-Saxon languages such as English. We also sought to provide more data regarding SLI in Catalan and/or Spanish, to add to the only study to focus on argument structure in these languages to date (Sanz-Torrent, Aguilar, Serrat \& Serra, 2001). In this study, the results showed that children with SLI avoid verbs that require more associated arguments and have a special difficulty with verbs that require movement of an entity (object or person) external to the action (generaly, transitives and ditransitives).

There are two major hypotheses to explain the linguistic difficulties of children with SLI. The first attributes these problems to deficits in linguistic representations. In this view, the problems are due to factors such as an implicit grammatical rules deficit (Gopnik, 1990; Gopnik \& Crago, 1991), restriction to the range of contexts to which rules are applied (Ingram \& Carr, 1994), problems with the acquisition of functional categories (Eyer \& Leonard, 1995) and a representational deficit of dependent relationship (Van der Lely, 1994).

A second explanation attributes these deficits to processing limitations in language comprehension and production. In this view, children with SLI have only limited processing capacity, which interferes with language acquisition and language processing (Ellis Weismer, 1994; Ellis Weismer, Evans \& Hesketh, 1999; Ellis Weismer \& Hesketh, 1996; Johnston, 1991; Leonard, 1998; Miller, Kail, Leonard, \& Tomblin, 2001). In children with SLI, complex linguistic operations may overwhelm the system's capacity, resulting in competition for 
resources between different stages of language processing and thus generating a computational trade-off that would benefit early stages of language processing and burden later ones.

According to this view, the argument-structure complexity may influence the number of verb argument omissions in children with SLI. If children with SLI have limited processing capacities, we can expect the verb argument omissions to be higher when the argument complexity increases. If the omissions are due to deficits in linguistic representations, then we can expect no differences in the number of omissions based on differences in argumentstructure complexity.

The main goal of the study described here is to analyse the use of different verb types (one-, two- and three-verb argument) and thematic role omissions in two Romance languages with a rich morphology and flexible order, produced by children with SLI using different methods. We also want to provide data for younger children and earlier developmental stages (e.g. the pre-school stage), for which fewer reports are available due to the difficulty of detection and diagnosis, even though this is a key stage in the process of acquiring verbs and their complements, especially in the case of children with SLI given their delayed acquisition.

To do this, we carried out three studies. In the first, we analyzed if children with SLI make more verb argument omission in spontaneous speech than their controls. In the second, we also analyzed the verb argument omissions in elicited verbs using videos of actions. Finally, in the third study we elicited verbs of action using static pictures with different argument structures in order to check if greater argument complexity generated more argument omissions.

\section{STUDY 1}

The aim of this study was to determine if children with SLI showed more argument omissions than two groups of control children. As data from English is controversial on this point, we wanted to analyze it in two Romance languages like Catalan and Spanish. To do this we carried out a longitudinal study (over a period of one year) in which we analyzed the children's verb argument omissions in spontaneous conversations involving interactions with their speech therapist.

\section{Methodology}

\section{Participants}

For Study 1 the sample comprised six children with SLI, all Catalan/Spanish bilinguals, along with their corresponding MLU-w and age-matched controls that were also matched for sex. Language data were obtained for two time periods: at 3.6 years and one year later. This study (like Studies 2 and 3) did not make any distinction between children with different linguistic backgrounds (that is, Catalan, Spanish or CatalanSpanish bilingual). The linguistic situation in Catalonia means that it is very difficult to separate monolingual and bilingual children. For a review of Catalan and Spanish bilingualism and SLI, see the recent study by SanzTorrent, Badia and Serra (2008). This study confirms that the bilingual context has minimal influence on the development of language impairment, at least from the point of view of code mixing and in typologically similar languages such as Spanish and Catalan. All the children had been diagnosed 
with SLI by CREDA centres in Catalonia and speech-language therapists and were receiving language intervention in a special school at the time of the study. Tests included the Wechsler Intelligence Scale for Children (WISC-R; Wechsler, Cordero, \& de la Cruz, 1993) or the Kaufman Brief Intelligence Test (KBIT-2; Kaufman \& Kaufman, 2004). Language ability was assessed by the Spanish version of Peabody III (Dunn, Dunn \& Arribas, 2006) and the Child Language Scale (ELI; Saborit \& Julián, 2005) ${ }^{1}$.

TABLE I

Sample Description

\begin{tabular}{lllllllll}
\hline$N$ & Gender & Age T1 & Age T2 & NVIQ & Language & $\begin{array}{l}\text { Parents' } \\
\text { Language }\end{array}$ & $\begin{array}{l}\text { Interview } \\
\text { language }\end{array}$ & Group \\
\hline 1 & Male & $4 ; 01$ & $5 ; 01$ & 104 & Bil. & Bil. & Bil. & SLI \\
2 & Male & $3 ; 05$ & $4 ; 07$ & 86 & Bil. & Spa. & Bil. & SLI \\
3 & Male & $3 ; 10$ & $4 ; 09$ & 110 & Bil. & Cat. & Cat. & SLI \\
4 & Female & $3 ; 10$ & $4 ; 10$ & 86 & Bil. & Bil. & Spa. & SLI \\
5 & Male & $3 ; 07$ & $4 ; 10$ & 110 & Bil. & Cat. & Cat. & SLI \\
6 & Male & $3 ; 07$ & $4 ; 08$ & 110 & Bil. & Bil. & Bil. & SLI \\
1 & Male & $4 ; 03$ & $5 ; 03$ & - & Bil. & Cat. & Cat. & AgeControl \\
2 & Male & $3 ; 07$ & $4 ; 07$ & - & Bil. & Spa. & Bil. & AgeControl \\
3 & Male & $4 ; 00$ & $4 ; 10$ & - & Bil. & Cat. & Cat. & AgeControl \\
4 & Female & $3 ; 06$ & $4 ; 09$ & - & Bil. & Bil. & Spa. & AgeControl \\
5 & Male & $3 ; 09$ & $4 ; 10$ & - & Bil. & Cat. & Cat. & AgeControl \\
6 & Male & $3 ; 07$ & $4 ; 09$ & - & Bil. & Bil. & Bil. & AgeControl \\
1 & Male & $2 ; 03$ & $2 ; 07$ & - & Bil. & Bil. & Bil. & MLU-wContr. \\
2 & Female & $1 ; 11$ & $3 ; 01$ & - & Bil. & Bil. & Cat. & MLU-wContr. \\
3 & Male & $2 ; 05$ & $2 ; 11$ & - & Bil. & Cat. & Cat. & MLU-wContr. \\
4 & Female & $2 ; 08$ & $3 ; 00$ & - & Bil. & Cat. & Cat. & MLU-wContr. \\
5 & Male & $2 ; 08$ & $3 ; 08$ & - & Bil. & Bil. & Cat. & MLU-wContr. \\
6 & Male & $2 ; 02$ & $3 ; 09$ & - & Bil. & Bil. & Bil. & MLU-wContr. \\
\hline
\end{tabular}

NVIQ: Non-verbal intelligence quotient; Bil: both languages; Cat: Catalan; Spa: Spanish

\section{Procedure}

The setting was a 45-minute play interaction between a known adult or speech therapist and the children. The data for participants from the first two groups (children with SLI and age-matched controls) were obtained via audiovisual recordings of the interaction between the speech therapist and child in two contexts (spontaneous conversation and semi-directed tasks set by the therapist). The data for participants in the MLU-w control group were obtained via audiovisual recordings of interactions with adults (examiner, father or mother) during play or everyday family situations (bath-time, meals, etc.). The sessions were conducted in either or both of the two languages depending on the dynamics of the conversation and the child's preferences. They were videotaped, transcribed, coded and analysed by using the CHILDES programs (MacWhinney, 2000).

All coded data (10,390 productions and 4,068 verbs) were analyzed using CLAN programs. Calculations were made using the mean proportion of each category or group of categories (whichever was more appropriate) for each group. Omissions were computed according to the potential total of the omitted category or the group of omitted categories. The potential total is the number of times that this category was required - in other words, the number of times that the category was executed plus the number of times that it had to be executed. 
The statistical analysis used non-parametric tests for comparison of means (Mann-Whitney U) for the between-group comparisons and the Wilcoxon test for the within-group comparisons.

\section{Results}

Below we present the productions of verbs classified according to the number of arguments they obligatorily require (Table II). Verbs were classified according to the context and without taking into account the actual argument structure employed, i.e. the fact that a verb is classified as " 2 arguments" does not necessarily mean that this argument structure was employed in the production.

At the first study point (T1) the groups differ in their use of the three types of verbs (those that require one, two or three arguments). The verbs most frequently used by the control groups were those involving two arguments, followed by verbs that only require one. Verbs such as posar (to put/to put on) or donar (to give) that require three arguments were the least used. In contrast, the behaviour of the SLI group differed significantly: the most widely-used verbs were those requiring the fewest arguments, for example, dormir (to sleep) or jugar (to play), which account for $64 \%$ of productions, and the children with SLI made no use of verbs that obligatorily require three arguments.

TABLE II

Proportion of verbs according to the number of arguments they require by group at Time 1 and Time 2

\begin{tabular}{llll}
\hline Time1 & SLI & Control-AGE & Control-MLUw \\
\hline
\end{tabular}

Verbs according to $\mathbf{N}$ arguments

\begin{tabular}{lllllll} 
1Argument & .64 & $(.24)$ & .23 & $(.07)^{*}$ & .22 & $(.10)^{*}$ \\
2Arguments & .35 & $(.24)$ & .71 & $(.06)^{*}$ & .71 & $(.09)^{*}$ \\
3Arguments & $0^{* *}$ & $(.00)$ & .04 & $(.01)^{*}$ & .06 & $(.05)^{*}$ \\
\hline Time2 & SLI & & Control-AGE & \multicolumn{2}{c}{ Control-MLUw } \\
\hline
\end{tabular}

Verbs according to $\mathbf{N}$ arguments

\begin{tabular}{lllllll} 
1Argument & .35 & $(.10)$ & .23 & $(.07)^{*}$ & .25 & $(.04)$ \\
2Arguments & .59 & $(.09)$ & .67 & $(.03)$ & .67 & $(.04)^{*}$ \\
3Arguments & $.04 * *$ & $(.05)$ & .09 & $(.04)^{*}$ & .07 & $(.02)^{*}$ \\
\hline
\end{tabular}

The data are given as means of proportions. In brackets: SD. Asterisk: $p<0.05$. Double asterisk: Within-group differences for children with SLI between T1 and T2.

By the second study point the use of two-argument verbs by the SLI group had increased, although the figure was still lower than the percentage for the group of younger children ( $59 \%$ vs. $67 \%$ ). There also continued to be a clear difference in the use of verbs that were the simplest in terms of argument, at least when compared to the age-matched controls (35\% vs. 23\%). The difference in production was greatest with respect to verbs that obligatorily require three arguments (only $4 \%$ for the SLI group vs. $9 \%$ and $7 \%$ for control groups).

Table 3 shows the arguments produced in verb statements, specifically, in the thematic roles to which the complements refer. The frequency of the codes for thematic roles shows that the most widely used was Theme (with 53\%), followed by Agent (at 29\%). Locative was the third most frequent role (11\%). Other less common roles were Patient and Beneficiary. This means that the verb productions of children with SLI were mainly complemented (in the event that there was an explicit complement) by the Agent and the Theme. 
TABLE III

Proportion of thematic roles at Time 1 and Time 2

\begin{tabular}{lllllll}
\hline Time1 & SLI & & AGE & & MLUw \\
\hline Theme & $.53^{* *}$ & $(.26)$ & .40 & $(.12)$ & .46 & $(.08)$ \\
Agent & .29 & $.20)$ & .20 & $(.07)$ & .15 & $(.18)$ \\
Locative & .11 & $(.13)$ & .11 & $(.04)$ & .11 & $(.08)$ \\
Patient & .05 & $(.08)$ & .06 & $(.06)$ & .03 & $(.02)$ \\
Beneficiary & .02 & $(.04)$ & .02 & $(.02)$ & .01 & $(.01)$ \\
Source & .00 & $(.00)$ & .00 & $(.00)$ & .00 & $(.00)$ \\
Goal & .00 & $(.00)$ & .02 & $(.02)^{*}$ & .02 & $(.02)$ \\
Instrument & .00 & $(.00)$ & .01 & $(.00)^{*}$ & .01 & $(.02)$ \\
\hline Time2 & SLI & & AGE & & MLU-w & \\
\hline Theme & $.34 * *$ & $(.08)$ & .41 & $(.08)$ & .43 & $(.07)^{*}$ \\
Agent & .27 & $(.06)$ & .20 & $(.04)^{*}$ & .22 & $(.03)$ \\
Locative & .17 & $(.08)$ & .12 & $(.03)$ & .09 & $(.04)^{*}$ \\
Patient & .01 & $(.09)$ & .05 & $(.03)^{*}$ & .04 & $(.05)$ \\
Goal & .02 & $(.03)$ & .02 & $(.01)$ & .009 & $(.01)$ \\
Beneficiary & .01 & $(.01)$ & .01 & $(.01)$ & .005 & $(.007)$ \\
Instrument & .006 & $(.01)$ & .01 & $(.01)$ & .02 & $(.01)^{*}$ \\
Source & .00 & $(.00)$ & .01 & $(.00)^{*}$ & .00 & $(.00)$ \\
\hline
\end{tabular}

The classification of roles included fifteen categories but only the main thematic roles are depicted in the table. The data are given as means of proportions. In brackets: standard deviation. Asterisk: $p<0.05$. Double asterisk: Within-group differences for children with SLI between $\mathrm{T} 1$ and $\mathrm{T} 2$.

In the lower half of table III the same data are presented for the mean age of 4 years 9 months (T2). Here the thematic role most used by children with SLI was Theme (with 34\%), followed by Agent (27\%) and Locative (17\%). The lowest percentages corresponded to the roles of Patient and Beneficiary $(1 \%)$ and, finally, Instrument $(0.6 \%)$. Compared with the two control groups it can be seen that children with SLI employ less diversity of arguments at $\mathrm{T} 1$, and that there is a difference in the distribution of roles at T2.

To complete the presentation of results for the first study, table IV shows the data for argument omissions ${ }^{2}$. Omissions of obligatory arguments or inadequate ellipsis in the obligatory context are omission of the complete phrase (the nominal or prepositional phrase) or the pronominal form of the constituent: for example, "tu dóna/tu da/you give" without the theme "això/esto/this" and without the receiver ("a ell/a él/to him").

The most noteworthy finding for argument omissions is that children with SLI make a greater proportion of omissions than do age-matched controls, and even more than the younger children at the second study point. Between 9 and $13 \%$ of occasions when an argument would be expected, children with SLI failed to employ one.

Focusing again on the SLI group, it can be seen that the thematic role most often omitted was that of Agent (7\% of occasions), followed by Theme $(4 \%)$. The other roles associated with a lower percentage of omissions were Locative (1\%) and Beneficiary and Patient (both $0.3 \%$ ). However, these data by category do not differ significantly from those of control children, even though the percentages among controls are lower in most categories. Finally, the most frequent omissions in the control groups also corresponded to the roles of Theme and Agent, although these children show a wider 
TABLE IV

Distribution of argument omissions with respect to thematic roles at Time 1 and Time 2

\begin{tabular}{|c|c|c|c|c|c|c|}
\hline \multirow{2}{*}{$\frac{\text { Time 1 }}{\text { Agent }^{6}}$} & \multicolumn{2}{|l|}{ SLI } & \multicolumn{2}{|c|}{ Control-AGE } & \multicolumn{2}{|c|}{ Control-MLUw } \\
\hline & .07 & $(.11)$ & .01 & $(.01)$ & .02 & $(.02)$ \\
\hline Theme & $.04 * *$ & $(.01)$ & .02 & $(.01)$ & .05 & $(.04)$ \\
\hline Locative & .01 & $(.03)$ & .01 & $(.01)$ & .01 & $(.02)$ \\
\hline Beneficiary & .00 & $(.02)$ & .00 & $(.00)$ & .01 & $(.01)$ \\
\hline Patient & .00 & $(.01)$ & .00 & $(.00)$ & .04 & $(.01)$ \\
\hline Source & 0 & 0 & .00 & $(.00)$ & .00 & .00 \\
\hline Goal & .00 & $(.00)$ & .00 & $(.01)$ & .00 & $(.00)$ \\
\hline Total & .13 & $(.09)$ & .05 & $(.03)(*)$ & .10 & $(.06)$ \\
\hline
\end{tabular}

Time2

\begin{tabular}{lllllll}
\hline Theme & $.05 * *$ & $(.00)$ & .02 & $(.01)^{*}$ & .02 & $(.01)^{*}$ \\
Agent & .03 & $.03)$ & .01 & $(.01)$ & .00 & $(.01)^{*}$ \\
Beneficiary & .01 & $(.01)$ & 0 & 0 & 0 & 0 \\
Patient & .00 & $(.01)$ & .00 & $(.00)$ & .00 & $(.00)$ \\
Locative & .00 & $(.01)$ & .01 & $(.01)$ & .00 & $.00)$ \\
Recipient & .00 & $(.00)$ & .00 & $(.00)$ & .00 & $(.00)$ \\
Source & .00 & $(.00)$ & .00 & $(.00)$ & .00 & $(.00)$ \\
Goal & .00 & $(.00)$ & .00 & $(.00)$ & .00 & $(.00)$ \\
\hline Total & .09 & $(.07)$ & .05 & $(.03)(*)$ & .03 & $(.02)(*)$ \\
\hline
\end{tabular}

The classification of roles included fifteen categories but only the main thematic roles omitted by children with SLI are depicted in the table. The values are means. In brackets: standard deviation. Asterisk: $p<0.05$. Asterisk in brackets: $p<0.065$. Double asterisk: Within-group differences for children with SLI between T1 and T2.

distribution, in line with the fact that they also produced a greater diversity of arguments.

The lower half of table IV shows that at T2 the thematic role most often omitted by the SLI group was Theme (5\%), followed by Agent (3\%) and Beneficiary (1\%). Other errors with lower percentages were Locative and Patient ( $0.4 \%$ of omissions) and, finally, the category Recipient $(0.05 \%)$. In contrast, age-matched controls made fewer errors of this type. Although the most frequently omitted role was once again Theme, the figure of $2 \%$ was lower than in the SLI group; the second most common omission was for the category Locative (1\%). With regard to the Theme it can be seen that the younger children make the same percentage of omissions as do the agematched controls and that both differ from the study group. Another omission that reveals a difference between the SLI group and MLU-w controls is that for the role of Agent, with respect to which the control group makes fewer omissions $(0.04 \%)$. The main finding at this second study point is that although the number of omissions made by the SLI group has decreased, it remains very high and significantly different from the number committed by controls.

Finally, the above tables show, marked by double asterisks, the data which changed in the SLI group between the two time points. Children with SLI show an improvement in terms of the presence of three-argument verbs and a greater diversity of arguments, illustrated by Theme. There is also an increased number of errors with transitive verbs and, consequently, of omissions with regard to the thematic role of Theme. 


\section{Discussion}

The common pattern of results between the two study points means that children with SLI showed a productive profile that differs from that of the MLU-w and age-matched control groups; this profile comprises simplification (verbs of low argument complexity, use of more prototypical arguments and rare use of adjuncts) and difficulty (obligatory argument errors and omissions). It can be seen that the two most frequent roles (Theme and Agent) are those that are most often omitted when required by the context.

It can also be seen that children with SLI have difficulty, either with regard to learning verbs with a more complex argument structure or in terms of using an avoidance strategy related precisely to the number of elements required. In fact, children with SLI make more frequent use of verbs with a simple argument structure: at T1 they use single-argument verbs and at T2 verbs with two arguments, but at both points there are very few examples that require three arguments. This is consistent with other studies in English that have reported special differences with regard to three-argument verbs (Thordardottir and Weismer, 2002).

\section{STUDY 2}

The previous study showed differences in the use of verbs with different argument structures and the types of argument omitted. However, the context was spontaneous speech, where while the language that was analyzed was in natural context, the number of verbs and the situations where they were produced were not controlled. The aim of the second study was to determine more clearly whether the difficulties that children with SLI have with verbs were accompanied by difficulties with their argument structure. To this end, we elicited sentences using videos that depicted events. We analysed whether children with SLI opted to produce simple argument structures or made omissions in the structure produced, despite being capable of producing the verb target in a denominative way.

\section{Methodology}

\section{Participants}

The sample comprised eight children with SLI, both monolinguals and Catalan/Spanish bilinguals, along with their corresponding MLU-w and agematched controls. The sample was selected according to criteria used in Study 1 , but all the children were different.

\section{Stimuli}

Participants were presented with a total of fifteen animated visual stimuli lasting between 3 and 25 seconds. The stimuli were events involving movement and state changes (see Appendix A). For the preparation of visual stimuli we followed the notion of event proposed by Talmy (2000), which conceptualizes the event as a single entity that has a particular type of internal structure and a degree of structural complexity. All the selected stimuli could be described by means of a verb that was familiar to the children (for example, to jump, to get down/off, to break, to paint, etc.). A video archive was created comprising the fifteen stimuli used in the study ${ }^{3}$. 
TABLE V

Sample description for the SLI and control groups

\begin{tabular}{llllll}
\hline $\mathbf{N}$ & Gender & Age & NVIQ & Language & Group \\
\hline 1 & Male & $4 ; 09$ & 110 & Bil. & SLI \\
2 & Male & $5 ; 11$ & 106 & Bil. & SLI \\
3 & Male & $5 ; 05$ & 108 & Bil. & SLI \\
4 & Male & $4 ; 10$ & 90 & Bil. & SLI \\
5 & Male & $5 ; 00$ & 105 & Bil. & SLI \\
6 & Male & $4 ; 11$ & 98 & Bil. & SLI \\
7 & Female & $5 ; 07$ & 105 & Cat & SLI \\
8 & Female & $4 ; 11$ & 108 & Cat & SLI \\
1 & Male & $4 ; 08$ & & Bil. & AgeControl \\
2 & Male & $5 ; 03$ & & Bil. & AgeControl \\
3 & Male & $4 ; 10$ & & Bil. & AgeControl \\
4 & Male & $4 ; 07$ & & Bil. & AgeControl \\
5 & Male & $4 ; 10$ & & Bil. & AgeControl \\
6 & Male & $4 ; 11$ & & Bil. & AgeControl \\
7 & Female & $5 ; 05$ & & Cat & AgeControl \\
8 & Female & $4 ; 10$ & & Cat & AgeControl \\
1 & Male & $3 ; 03$ & & Bil. & MLUw-Control \\
2 & Male & $3 ; 06$ & & Bil. & MLUw-Control \\
3 & Male & $3 ; 05$ & & Bil. & MLUw-Control \\
4 & Male & $3 ; 02$ & & Bil. & MLUw-Control \\
5 & Male & $3 ; 04$ & & Bil. & MLUw-Control \\
6 & Male & $3 ; 02$ & & Bil. & MLUw-Control \\
7 & Female & $3 ; 02$ & & Cat & MLUw-Control \\
8 & Female & $3 ; 01$ & & Cat & MLUw-Control \\
\hline
\end{tabular}

NVIQ: Non-verbal intelligence quotient; Bil: both languages; Cat: Catalan

\section{Procedure}

The procedure consisted of the presentation of the selected stimuli, which were shown in the same order to all the children. Prior to being presented with the stimuli the children were instructed about the task they had to perform. After each stimulus was presented the experimenter said: "Tell me what you bave seen"; if the child failed to respond or offered an incomplete response the experimenter then asked: "What happened?".

Each child was examined in his/her mother tongue. The stimuli were created so as to be equivalent in Spanish and Catalan (with the same frequency and the same argument structure). This stage lasted approximately 25 minutes. The sessions for all three groups were video-recorded. The data was analyzed in accordance with the procedure and statistical methods described in Study 1.

\section{Results}

The results refer to argument structure (number of arguments and type of thematic role). Table VI shows the productions according to the arguments they contain. Children with SLI restricted themselves notably more than the two control groups to the production of sentences with no arguments (isolated verbs) or only one argument (e.g. "trencat! / Roto! / Break!" or "deixa aquil deja aqui / leave here"), There were significant differences with respect to controls regarding the combined percentage for productions involving zero or one argument. Children with SLI produced significantly fewer sentences involving two or three arguments, thus illustrating a lower level of production for more complex argument structures. Although the most 
complex argument structure was the least used by all three groups, the agematched controls were able to use it on $6.6 \%$ of occasions, while the figure for the MLU groups was lower, at $1.6 \%$. However, children with SLI produced no sentences containing three arguments, a difference that was significant with respect to the age control group.

TABLE VI

Distribution of productions by number of arguments

\begin{tabular}{lccc}
\hline & SLI & Control-AGE & Control-MLU \\
\hline $\begin{array}{l}\text { Combined percentage for productions } \\
\text { with 0-1 arguments }\end{array}$ & $.87(.10)$ & $.69(.14)(*)$ & $.73(.11)$ \\
Productions with 2 arguments & $.12(.06)$ & $.22(.12)^{*}$ & $.23(.12)^{*}$ \\
Productions with 3 arguments & $0(0)$ & $.06(.05)^{*}$ & $.01(.03)$ \\
\hline
\end{tabular}

The values are means of proportions by group. In brackets: standard deviation.

Between-groups significance (SLI-AGE/SLI-MLU; Asterisk: $p<0.05$; Asterisk in brackets: $p<$ $0.065)$.

As can be seen in table VII the highest number of argument omissions occurred in all groups when the argument function was Theme (e.g. "pingu neteja / pingu limpial pingu cleans"). It is noteworthy that the second most frequent omission made by children with SLI corresponded to the thematic role of Agent, whereas for both control groups the second most common omission was for the locative function. However, it should be pointed out that Agent omissions occurred mostly due to the omission of verb auxiliaries, which results in the omission of the thematic role of Agent unless the agent has been explicitly marked elsewhere in the sentence.

TABLE VII

Argument omissions according to thematic roles

\begin{tabular}{llll}
\hline Argument omission & SLI & Control-AGE & Control-MLU \\
\hline THEME & $.07(.02)$ & $.02(.01)^{*}$ & $.05(.01)$ \\
AGENT & $.04(.01)$ & $0^{*}$ & $.002(.00)^{*}$ \\
PATIENT & $.02(, 01)$ & $.003(.00)^{*}$ & $.01(.01)$ \\
SOURCE & $.01(0.8)$ & $.01(.009)$ & $.006(.01)$ \\
LOCATIVE & $.008(.00)$ & $.0001(.00)$ & $.01(.01)$ \\
RECIPIENT & $.01(.005)$ & 0 & $.007(.01)$ \\
GOAL & $.002(.00)$ & $.003(.00)$ & $.006(.00)$ \\
\hline TOTAL & $.19(.06)$ & $.06(.05)^{*}$ & $.09(.05)^{*}$
\end{tabular}

The values are means of proportions by group. In brackets: standard deviation. Between-groups significance (SLI-AGE/SLI-MLU; Asterisk: $p<0.05$ ).

The total proportion of omissions shows that children with SLI more often omit arguments that are obligatory with respect to the verb that they themselves have produced.

\section{Discussion}

The results show that when describing events children with SLI tend to use productions with few arguments, and also that the two control groups make fewer argument omissions than do children with language impairment; indeed, children with SLI make more than three times as many omissions as their age- 
matched controls and almost twice as many as the MLU group. These differences between the SLI and both control groups were significant as we had found in Study 1.

\section{STUDY 3}

Study 2 showed similar results to study 1 . In this study, we wanted to evaluate if the problems in verb argument structure shown by children with SLI in the previous studies are due to deficits in processing limitations. In order to do this, we compared the production of verbs and arguments according to the event's argument complexity. We used static pictures that depicted events with different argument structure to analyse whether children with SLI opted to produce simple argument structures or made omissions in the structure produced.

\section{METHODOLOGY}

\section{Participants}

The sample comprised 22 children who were bilingual in Catalan and Spanish (11 children with SLI and 11 age-matched controls). Children were selected according to the criteria described in Study 1. The children selected for the study had been diagnosed with SLI by the School Educational Psychology Service (SPE) Castelló C-04, and by the CREDA in Girona, and none of them had participated in Studies 1 and 2.

TABLE VIII

Characteristics of the SLI group and the control group

\begin{tabular}{llllllll}
\hline $\begin{array}{l}\text { SLI } \\
\text { group }\end{array}$ & Sex & Age & NVIQ & $\begin{array}{l}\text { Mother } \\
\text { tongue }\end{array}$ & $\begin{array}{l}\text { Control } \\
\text { group - } \\
\text { Sex }\end{array}$ & $\begin{array}{l}\text { Control } \\
\text { group - } \\
\text { Age }\end{array}$ & $\begin{array}{l}\text { Control } \\
\text { group - } \\
\text { Mother } \\
\text { tongue }\end{array}$ \\
\hline 01 & Male & $05 ; 10$ & 102 & Spanish & Male & $05 ; 09$ & Spanish \\
02 & Female & $06 ; 05$ & 86 & Spanish & Female & $06 ; 07$ & Spanish \\
03 & Female & $06 ; 06$ & 99 & Spanish & Female & $06 ; 06$ & Spanish \\
04 & Male & $06 ; 06$ & 94 & Catalan & Male & $06 ; 07$ & Catalan \\
05 & Female & $03 ; 08$ & 97 & Spanish & Female & $03 ; 06$ & Spanish \\
05 & Male & $05 ; 10$ & 106 & Spanish & Female & $05 ; 10$ & Spanish \\
07 & Male & $04 ; 06$ & 110 & Spanish & Male & $04 ; 08$ & Catalan \\
08 & Female & $06 ; 05$ & 114 & Spanish & Male & $06 ; 06$ & Spanish \\
09 & Female & $05 ; 04$ & 105 & Catalan & Female & $05 ; 00$ & Catalan \\
10 & Male & $05 ; 04$ & 118 & Catalan & Female & $05 ; 03$ & Catalan \\
11 & Female & $04 ; 04$ & 110 & Spanish & Female & $04 ; 07$ & Catalan \\
\hline
\end{tabular}

NVIQ: Non-verbal intelligence quotient

The control group was equivalent in age, sex and mother tongue to their counterparts in the SLI group. The control sample was selected from among the classmates of each child with SLI ${ }^{4}$. Each child was examined in his/her mother tongue. The stimuli were created to be equivalent in Spanish and Catalan (with the same frequency and argument structure).

\section{Procedure}

Participants sat at a distance of 22 inches from a 15-inch lap top, set to $1280 \times 800$ pixels. The procedure consisted of the presentation of 39 images 
(plus 7 filler images). All 39 images referred to frequent and familiar verbs. Thirteen images had one argument, another thirteen had two and a final thirteen had three (see Appendix B).

FIGURE 1

Example of events with one, two and three arguments
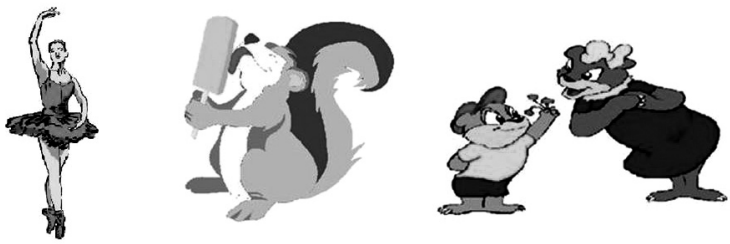

We chose images that were appropriate for children. All the images were in the same style and contained the same shapes, sizes and colours. In addition, the number of participating entities and the relationships between them were manipulated, so that the participant would produce a specific target sentence. The children were instructed to: "Tell us what is happening here". The images were presented in the same order (a random order of events 1,2 and 3) and the exposure time was the same for all the children (10 seconds). Between the presentations of each image, a centering image was shown for 2 seconds. Subsequently, the child's production was recorded on audio and video. The data was analyzed according to the procedure and statistical methods described in Study 1 .

\section{Results}

The transcribed productions were categorized as correct or incorrect. Sentences with the target verb or a synonymous one with the same argument structure were coded as correct responses, and all the other responses were coded as incorrect. We didn't take into account here whether the children made any grammatical errors (i.e. errors in verb conjugation, noun and verb agreement, etc.) because the aim was only to analyze accuracy in identifying events. This allowed us to assess whether children with SLI showed problems in recognizing actions with different verb argument structure compared to their age control. As we can see in Table IX, the group of children with SLI mainly responded in a way that was not relevant to the target. Indeed, the percentage of correct responses in the SLI group was significantly different from that in the control group.

TABLE IX

Proportion of correct responses

\begin{tabular}{lll}
\hline Correct responses & SLI & Control-AGE \\
\hline 1argumentlevent & $.50(.27)$ & $.68(.17)$ \\
2arguments/event & $.50(.29)$ & $.75(.16)^{*}$ \\
3argumentslevent & $.36(.27)$ & $.62(.22)^{*}$ \\
\hline Correct responses & $.45(.28)$ & $.68(.19)$ \\
\hline
\end{tabular}

The values are means of proportions by group. In brackets: SD.

Between-groups significance (Asterisk: $p<0.05$ ).

We also analyzed whether there were differences in the proportion of arguments produced in the correct responses. Table $\mathrm{X}$ shows the data displayed according to the number of arguments in an event. In particular, the SLI group's 
responses differed from those of the control group in events with two or three arguments.

TABLE X

Proportion of arguments

\begin{tabular}{lll}
\hline Arguments & SLI & Control-AGE \\
\hline 1 argumentlevent & $.89(.30)$ & $.98(.04)$ \\
2 arguments/event & $.78(.30)$ & $.96(.03)^{*}$ \\
3 arguments/event & $.71(.26)$ & $.88(.06)^{*}$ \\
\hline
\end{tabular}

The values are means of proportions by group. In brackets: SD.

Between-groups significance (Asterisk: $p<0.05$ ).

Analysis of the number of arguments used according to the type of event (1, 2 or 3 arguments) revealed that the most significant differences between the groups corresponded to the most complex events.

TABLE XI

Proportion of argument omission

\begin{tabular}{lll}
\hline Argument omissions & SLI & Control-AGE \\
\hline Theme & $.17(.30)$ & $.02(.02)^{*}$ \\
Recipient & $.03(.03)$ & $.01(.01)$ \\
Others & $.01(.03)$ & $.008(.00)$ \\
\hline
\end{tabular}

The values are means of proportions by group. In brackets: SD.

Between-groups significance (Asterisk: $p<0.05$ ).

Finally, we analyzed the thematic roles used with respect to those that would be expected in correct responses. This revealed that children with SLI formed fewer arguments than did controls; in other words, they made more omissions of obligatory arguments, especially for Themes.

\section{Discussion}

The data showed that children with SLI were less accurate when describing an event, producing fewer verb targets and fewer arguments than their age controls. Most of their responses were incomplete responses (either failing to answer or only describing isolated parts of the event) or described other subevents that did not give relational meaning to the elements involved in the event. Here we noted that the SLI group had great difficulty in describing events related to three-argument verbs. This is in agreement with the findings of Studies 1 and 2, which showed that children avoided or had difficulty with three-argument verbs in a sample ranging in age from 3 years 9 months to 4 years 9 months.

Moreover, even when their responses were considered to be correct the SLI group continued to perform worse than controls when describing obligatory arguments. Indeed, they omitted over $20 \%$ of the expected arguments (as in Study 2). This difference was even more pronounced in verbs that took more arguments (for some verbs, children only produced $70 \%$ of the obligatory arguments). Similar values to these were found in Study 2. This type of error has also been found for other languages (de Jong, 1999; Fletcher \& Garman, 1988; Schelletter, Sinka, Fletcher \& Ingham, 1999, among others). In addition to the evidence that children with SLI use a simplification of verb arguments, they 
showed a poor pragmatic understanding of the information that had to be transmitted, as illustrated by subject elisions and the omission of the Theme in verbs where the object semantics were highly restricted.

\section{GENERAL DISCUSSION}

The first point to be made is that the specific data vary and depend heavily on the methodology used, i.e. the age of participants, the type of procedure employed (spontaneous speech, description of dynamic versus static events, etc.), the type of data treatment, etc. For example, omissions or errors are more likely to appear in situations where participants have to elicit specific structures or arguments. Likewise, they also depend on the criteria used to form categories (more rigorous, or broader). Age is an important factor in these data, since the younger the children are the more likely it is that they will make mistakes of this kind.

Nevertheless, the results do reveal that Catalan and Spanish speaking children with SLI have specific difficulties with the verb and its arguments, since they produce verbs with a simpler argument structure and make more argument omissions and inappropriate elisions.

In line with previous findings in English (i.e. Grela, 2003) the present results reveal a certain vulnerability with regard to the correct or incorrect use of arguments, illustrated by the limited diversity of arguments, a particular difficulty with some of them, and the omission of arguments in obligatory contexts. Overall, this suggests a difficulty with complementation (King \& Fletcher, 1993) and a reduced use of rule application (Ingram \& Carr, 1994). Children with SLI are more likely to omit one or more arguments in obligatory contexts, and when they do produce arguments correctly show a limited range of argument use. They display particular problems with the thematic role of Theme, which is frequently associated with the grammatical function of the direct object. Therefore, it can be stated that children with SLI also have difficulties with argument structure, whether due to an overload of general processing resources or to specific problems with this particular aspect (Grela \& Leonard, 1997). In this regard it is worth considering a point made by Pinker (1989), who suggested that many argument structure errors are related to projecting verb semantics onto syntax.

In the light of the present results for Catalan and Spanish one could speculate as to whether the problem might actually be more marked. One explanation for these contrasting findings would lie in the characteristics of these two languages, in which the syntactic order is more flexible than in Anglo-Saxon languages; this may be an aspect to which children would thus pay less attention, and they would find it more difficult to identify clear patterns in the argument structure (for example, from the mapping of thematic roles with argument functions or from the obligatory arguments for a given verb), all of which would affect both the semantic representation of the verb and knowledge of grammatical rules. According to the competition model (Bates \& MacWhinney, 1987) the course of language acquisition will inevitably differ as a function of the most informative cues, which compete, and also in accordance with the specific language being learnt.

With respect to the explanations for these difficulties, we have seen that the more complex the event is, the more difficulties of expression it presents. When the amount of information processing increases, the percentage of errors also increases. This suggests that children with SLI have limitations in processing complex events. Moreover, in the tasks reported here (especially in Studies 2 and 
3) there is an intimate relationship between linguistic representation and linguistic processing. In order to properly process the meaning of a verb and its arguments, children must have semantic representations that guide their processing to the correct arguments in the correct order. Then, when they activate a verb it also activates its accompanying arguments, which they have to produce in order to construct an utterance in a sentence that makes complete sense. In the three experiments, the pattern of language production showed by children with SLI seems to indicate that they find it difficult to make unified, relational sense of the different elements constituting the event. They even had problems with verbs with only one argument. This suggests that children with SLI have an incomplete sense of a verb's semantic representation, which means they cannot rapidly identify the elements that accompany the action (or the verb), and make different mistakes such as verb target substitutions or arguments omissions. Other factors such as experience (world knowledge) and grammar practice may also play a significant role in any potential explanation of these data.

In sum, we conclude that a special and characteristic feature of Catalan and Spanish speaking children with SLI is their problems with verb argument structure, as witnessed by the simplification of arguments and argument omissions. The empirical data of this study suggest that these problems are due to problems with the semantic representation of verb argument structure and deficits in processing limitations.

\section{Notes}

${ }^{1}$ The ELI test includes several subtests, among others, for articulation, lexical reception and lexical production and provides an equivalent age and a percentile. Children with SLI had scores of at least -1.25 standard deviations below the mean in both test.Children also took a hearing screening at $25 \mathrm{~dB}$ for each ear at 500, 1000, 2000 and $4000 \mathrm{~Hz}$. Children with hearing problems were excluded from the sample. The case histories of all the children were taken by an educational psychologist, to rule out neurological dysfunctions and symptoms of impaired reciprocal social interaction or any restriction of activities. Moreover, speech therapists examined the oral structure and motor functions, as well as the respiratory dynamics, exhalation and rhythm.

${ }^{2}$ Omissions are counted over the potential total for each of the categories. Note that omissions of arguments which can take the subject position are included, even though we are analysing pro-drop languages in which subject elision is permitted if there is verb inflection. In these cases, an omission was only recorded if the subject had to be specified given the communicative situation. For example, in a situation involving different male and female dolls it was necessary to introduce the subject in order to know who the expression "posa aquî" (put here) referred to. It should be remembered that elisions were only counted when the linguistic or extra-linguistic context required the specification of arguments, despite their being optional.

${ }^{3}$ In this case the stimuli were fragments taken from VHS recordings of Pingu cartoons, and in order to create the archive this audiovisual material was digitalised and edited using the Pinnacle Studio program.

${ }^{4}$ Teachers were asked if the control subjects' language development was normal for their age. Children were not selected if they had a history of speech therapy or psychological therapy. In addition, teachers were asked to select children with normal academic performance. All of the children selected came from state schools in Catalonia and Valencia.

${ }^{5}$ In this case the omission or elision of the agent was not taken into account.

${ }^{6}$ This omission occurs when the production required role specification, either as an anaphoric option to give cohesion to the discourse, or because a non-inflected verb was used and the language context required an explicit marker of the person. In other words, it also includes inappropriate subject elisions.

\section{References}

Arapovic, D. \& ANDel, M. (2003). Morfoloske pogreske u diskursu djece s PJT [Morphological errors in discourse of children with SLI]. Hrvatska Revija za Rehabilitacijska Istrazivanja, 39, 11-16.

BAtes, E. \& MACWhinney, B. (1987). Competition, variation and language learning. In B. MacWhinney (Ed.), Mechanisms of language acquisition (pp. 157-194). Hillsdale, NJ: Lawrence Erlbaum.

BISHOP, D. (1997). Uncommon understanding. London: Psychology Press.

ClAHSEN, H. (1989). Grammatical characterization of developmental dysphasia. Linguistics, 27, 897-920.

Clahsen, H. (1991). Child language and developmental dysphasia. Amsterdam: John Benjamins.

COnti-Ramsden, G. \& Jones, M. (1997). Verb use in specific language impairment Journal of Speech and Hearing Research, 40, 1298-1313.

DE JONG, J. (1999). Specific Language impairment in Dutch: Inflectional Morphology and argument structure. Enxchede, NL: Print Partners Ipskamp. 
DunN, Ll., Dunn L. M. \& Arribas, D. (2006). PPVT-III Peabody, Test de Vocabulario en Imágenes. Madrid: TEA Ediciones.

ELLIS WeISMER, S. (1994). Factors influencing novel word learning and linguistic processing in children with specific language impairment. Paper presented at the Symposium on Research in Child Language Disorders, Madison, WI, June.

Ellis Weismer, S., Evans, J. \& Hesketh, L. (1999). An examination of verbal working memory capacity in children with specific language impairment. Journal of Speech and Hearing Research, 42, 1249-1260.

Ellis Weismer, S. \& HeSKeth, L. (1996). Lexical learning by children with specific language impairment: Effects of linguistic input presented at varying speaking rates. Journal of Speech and Hearing Research, 39, 177-190.

EYER, J. \& LEONARD, L. (1995). Functional categories and specific language impairment: A case study. Language Acquisition, 4, 177-203.

FleTCHER, P. \& Garman, M. (1988). Normal language development and language impairment: syntax and beyong. Clinical Linguistics \& Phonetics, 2, 97-113.

FleTCHER, P. \& PETERS, J. (1984). Characterizing language impairment in children: An exploratory study. Language testing, $1,33-49$.

GoPNIK, M. (1990). Feature-Blind Grammar and Dysphasia. Nature, 344, 715

GopNIK, M. \& Crago, M. B. (1991). Familial aggregation of a developmental language disorder. Cognition, 39, 1-50.

Grela, B. G. (2003). The omission of subject arguments in children with Specific Language Impairment. Clinicallinguistics Ephonetics, 17, 2, 153-169.

Grela, B. G. \& LeONARD, L. B. (1997). The use of subject arguments by children with SLI. Clinical Linguistics and Phonetics, $11,443-453$.

GrELA, B., \& LEONARD, L. B. (2000). The influence of argument structure complexity on the use of auxiliary verbs by children with SLI. Journal of Speech, Language, and Hearing Research, 43, 1115-1125.

GrimshaW, J. (2005). Semantic structure and semantic content in lexical representation. In J. Grimshaw, Words and Structure (pp. 75-89). Standford: CSLI Publications.

Hadley, P. \& Rice, M. (1996). Emergent uses of BE and DO: Evidence from children with specific language impairment. Language Acquisition, 5, 209-243.

HaNssON, K. (1997). Patterns of verb usage in Swedish children with SLI: An application of recent theories. First Language, $17,195-217$.

Ingram, D. \& CARR, L. (1994). When morphology ability exceeds syntactic ability: A case study. Paper presented at the Convention of the American Speech-Language-Hearing Association, New Orleans, November.

JACKENDOFF, R. (2002). Foundations of language: brain, meaning, grammar, evolution. Oxford, UK: Oxford University Press.

Johnston, J. R. (1991). Questions about cognition in children with specific language impairment. In J. F. Miller (Ed.), Research on child language disorders: A decade of progress (pp. 299-307). Austin, TX: Pro-Ed.

Kaufman, A. S. \& Kaufman, N. L. (2004). KBIT: Kaufman Brief Intelligence Test (KBIT, Spanish version). Madrid: TEA Editions.

KelLY, D. (1997). Patterns in verb use by preschoolers with normal language and specific language impairment. Applied Psycholinguistics, 18 (2), 199-218.

KeLLY, D. \& RICE, M. (1994). Preferences for verb interpretation in children with SLI. Journal of Speech and Hearing Research, 37, 182-192.

KeRSCHENSTEINER, M. \& HubER, W. (1975). Grammatical impairment in developmental aphasia. Cortex, 11, $264-282$.

KING, G. \& FleTCHER, P. (1993). Grammatical problems in school-age children with specific language impairment. Clinical Linguistic and Phonetics, 7, 339-352.

LEONARD, L. (1995). Functional categories in the grammars of children with specific language impairment. Journal of Speech and Hearing Research, 38, 1270-1283.

LEONARD, L. (1998). Specific Language Impairment. London: The MIT Press.

LEONARD, L. (2000). Specific language impairment across languages. In D. V. M. Bishop \& L. B. Leonard (Eds.), Speech and Language Impairments in Children: Causes, Characteristics, Intervention and Outcome (pp. 115-130). Hove: Psychology Press.

LEONARD, L., EYER, J., BEDORE, L. \& GRELA, B. (1997). Three accounts of the grammatical morpheme difficulties of Englishspeaking children with specific language impairment. Journal of Speech and Hearing Research, 40, 741-753.

LEVIN, B. \& RAPPAPORT H. M. (1995). Unaccusativity: At the syntax-lexical semantics interface. Cambridge, MA: MIT Press.

MACWhinney, B. (2000). CHILDES Project. Hillsdale, NJ: Lawrence Erlbaum Associates.

Miller C., KaIl R., Leonard L., Tomblin B. (2001). Speed of processing in children with specific language impairment. Journal of Speech and Hearing Research, 44 (2), 416-433.

PINKER, S. (1989). Language Acquisition. In D. N. Osherson \& H. Lasnik (Eds.), An invitation to cognitive science; Volume 1. Language (pp. 199-241). Cambridge, MA: MIT Press.

RICE, M. L. \& BODE, J. (1993). GAPS in the verb lexicons of children with SLI. First Language, 13, 113-131.

Rice, M. L. \& WexiER, K. (1996). Toward tense as a clinical marker of specific language impairment in English-speaking children. Journal of Speech and Hearing Research, 39, 1239-1257.

RICE, M. \& WEXLER, K. (1997). Higbly specified and long-term grammatical deficits appear in children with language impairments. Cambridge, MA: Department of Brain and Cognitive Sciences, MIT.

Rice, M., WeXler, K. \& CleAve, P. (1995). Specific language impairment as a period of extended optional infinitives. Journal of Speech and Hearing Research, 38, 850-863.

SABORIT, C. \& JULIÁN, J. P. (2005). ELI-L'Avaluació del Llenguatge Infantil. Castelló de la Plana: Universitat Jaume I.

Sanz-Torrent, M., Aguilar, E., Serrat, E. \& Serra, M. (2001). Verb Type Production in Catalan and Spanish Children with SLI. In M. Almgremm, A. Barreña, M. J. Ezeizabarrena, I. Idiazabal \& B. MacWhinney (Eds.), Research on Child Language Acquisition (pp. 909-922). Sommerville, MA: Cascadilla Press.

SAnZ-Torrent, M.; BADIA, I. \& Serra, M. (2008). Contributions from the bilingual Specific Language Impairment in Catalan and Spanish to the understanding of the normal and pathological language acquisition. In C. Pérez-Vidal, M. Juan-Garau \& A. Bel (Eds.), A portrait of the young in the new multilingual spain (pp. 135-158). Clevedon: Multilingual Matters.

Sanz-Torrent, M., Serrat, E., Andreu, Ll. \& Serra, M. (2008). Verb morphology in Catalan and Spanish in children with SLI: a developmental study. Clinical Linguistics and Phonetics, 22 (6), 459-474.

SChelletter, C., Sinka, I., FletCher, P. \& INGHAM, R. (1999). English speaking SLI children's use of locative/contact and causative alternations. In M. Garman, C. Letts, B. Richards, C. Schelletter \& S. Edwards (Eds.), Issues in normal and 
disordered child language: from phonology to narrative (pp. 106-117). Special Issue of The New Bulmershe Papers. Reading: University of Reading.

Talmy, L. (2000). Toward a Cognitive Semantics, vol. I: Concept Structuring Systems. Cambridge: MIT Press.

THORDARDOTTIR \& WEISMER S. E. (2002). Verb argument structure weakness in specific language impairment in relation to age and utterance length. Clinical Linguistics \& Phonetics, 16 (4), 233-250.

VAN DER LELY, H. (1994). Cannonical linking rules: forward versus reverse linking in normally developing and specifically language-impairment children. Cognition, 51, 29-72.

WatKins, R., RiCe, M. \& MOlTZ, C. (1993). Verb use by language-impaired and normally developing children. First Language, 13, 133-143.

WeCHSLER, D., CORDERO, A. \& DE LA CRUZ, M. V. (1993). Wechsler Intelligence Scale for Children, Revised (WISC-R, Spanish version). Madrid: TEA Editions.

\section{Appendix A}

List of verbs used as stimuli in the study 2

Target Verb
Menjar/Comer [Eat]
Deixar a/Dejar en [Leave]
Tirar [Throw]
Netejar/Limpiar [Clean]
Plorar/LLorar [Cry]
Trencar/Romper [Break]
Pujar/Subir [Climb]
Donar/Dar [Give]
Baixar/Bajar [Go down]
Saltar [Jump]
Llançar-se a/Lanzarse a [throw]
Dormir [Sleep]
Pintar [Paint]
Caure/Caer [Fall]
Jugar [Play]

\section{Appendix B}

List of verbs used as stimuli in the study 3

\begin{tabular}{ccc}
\hline One-argument verbs & Two-argument verbs & Three-argument verbs \\
\hline CaurelCaer & Tocar & Cordar/Atar \\
[Fall] & [Play] & [Tie] \\
Caminar & Agafar/Coger & Ensenyar/Enseñar \\
[Walk] & [Catch] & [Show] \\
Plorar/Llorar & Xupar/Chupar & Regalar \\
[Cry] & {$[$ Lick] } & [Give (a present)] \\
Dormir & Portar/Llevar & Trencar/Romper \\
[Sleep] & {$[$ Carry] } & {$[$ Break] } \\
BallarlBailar & Recollir/Recoger & Donar/Dar \\
[Dance] & {$[$ Pick up] } & [Give] \\
Volar & Obrir/Abrir & Tirar \\
{$[$ Fly] } & {$[$ Open] } & [Throw] \\
\hline
\end{tabular}

